\title{
ARQUITETURA MODERNA DE CAJAZEIRAS: A OBRA DA ARQUITETA JOSETE CLAUDINO
}

\author{
MODERN ARCHITECTURE OF CAJAZEIRAS: THE WORK OF THE \\ ARCHITECT JOSETE CLAUDINO
}

\author{
Elis Regina da Silva Carolino ${ }^{1}$ \\ Isabel Sobral de Abreu e Lima $^{2}$ \\ Mirela Davi de Melo ${ }^{3}$ \\ Marjorie Maria Abreu Gomes de Farias ${ }^{4}$ \\ Emanoella Bella Sarmento Salgueiro Eliziário Matias ${ }^{5}$ \\ Pollyanna Priscila de Souza Lima ${ }^{6}$
}

\footnotetext{
${ }^{1}$ Graduanda em Arquitetura e Urbanismo pela Faculdade Santa Maria - FSM.

${ }^{2}$ Arquiteta e Urbanista graduada pelo Centro universitário Maurício de Nassau de Recife em 2017 e Pós Graduada em Acústica Arquitetônica e lluminação pela Faculdade de Ciências Humanas ESUDA em 2018. Pós Graduanda em Docência em Ensino Superior pela Faculdade Santa Maria de Cajazeiras (FSM). Docente da Faculdade Santa Maria (FSM), tem experiência na área de Arquitetura e Urbanismo, com ênfase em Planejamento e Projetos de Acústica Arquitetônica, atuando principalmente com projetos, obras e consultoria.

${ }^{3}$ Possui graduação em Arquitetura e Urbanismo pela Universidade Federal da Paraíba (UFPB 2016), especialização em Gestão de Políticas do Patrimônio Cultural pela Faculdade Maurício de Nassau (2018) e mestrado em Desenvolvimento Urbano (MDU) pelo Departamento de Arquitetura e Urbanismo da Universidade Federal de Pernambuco (UFPE - 2019), canalizando seus estudos para o projeto paisagístico e o bem-estar. Exerce o cargo de arquiteto como técnica na Prefeitura Municipal de Marí/ PB desde 2016, atuando na elaboração de projetos arquitetônicos e urbanos. É docente na Faculdade Santa Maria (FSM) desde 2018.

${ }^{4}$ Arquiteta e Urbanista, graduada pela Universidade Federal da Paraíba (UFPB) (2013) e mestre pelo Programa de Pós-graduação em Arquitetura e Urbanismo da Universidade Federal da Paraíba (PPGAU-UFPB) (2015). Atualmente é professora do curso de Bacharelado em Arquitetura e Urbanismo da Faculdade Santa Maria - Cajazeiras-PB. Tem experiência ministrando aulas e trabalhando com iniciação científica nos seguintes temas: acessibilidade, mobilidade, avaliação pósocupação, sistema de espaços livres, avaliação pós-ocupação e representação e concepção de projeto.

5 Pesquisadora mestra (2015) pelo Programa de Pós Graduação em Arquitetura e Urbanismo, PPGAU - UFPB. Arquiteta e Urbanista, formada pela Universidade Federal da Paraíba (2011). Colaboradora do Laboratório de Acessibilidade (LACESSE) - UFPB desde 2012 e integrante do grupo de pesquisa Qualidade, Acessibilidade, Tecnologia e Percepção do Ambiente Construído, certificado UFPB e CNPq. Coordenadora e docente do curso de Arquitetura e Urbanismo da Faculdade Santa Maria (FSM) de Cajazeiras, na Paraíba.

${ }^{6}$ Arquiteta e Urbanista graduada pelo Centro Universitário de João Pessoa - UNIPÊ. Mestre em Qualidade do Ambiente Construído pelo Programa de Pós-Graduação em Arquitetura e Urbanismo PPGAU-UFPB. Atualmente é professora do curso de Arquitetura e Urbanismo da Faculdade Santa Maria e Faculdade Paraíso do Ceará- FAP atuando principalmente nos seguintes temas: bioclimatismo na arquitetura e urbanismo, Sustentabilidade, conforto ambiental das edificações, simulações computacionais, história da arquitetura moderna e contemporânea e Plataforma BIM.
} 
RESUMO: O presente trabalho traça um perfil a ser utilizado como repertório para buscar a aproximação entre as obras da arquiteta Josete Claudino e as tendências modernistas divulgadas pelos principais arquitetos deste movimento. Sem intenção de desprezar a história da arquitetura moderna, mas atenta ao ponto principal desta pesquisa que são as características do movimento modernista no Brasil, com enfoque para a região nordeste, foi construída uma estrutura que parte dos pontos criados por Le Corbusier para a arquitetura moderna ideal. Seguindo uma conexão lógica entre o modernismo internacional até chegar a Cajazeiras, que é o local onde se localiza o objeto de estudo que foi utilizado para análise, percebeu-se, então, a necessidade de uma narrativa que contextualizou desde a chegada dessa escola arquitetônica ao país, com Gregory Warchavchik, passando pelas escolas paulistas e cariocas, adentrando na construção de Brasília apenas para manter a ordem cronológica. $\mathrm{O}$ fato que realmente esteve presente no fechamento desta sequência foi a vinda do arquiteto Acácio Gil Borsoi para Recife, e, em seguida, para Paraíba. Pela proximidade temporal e espacial, Gil Borsoi foi determinado como referência para as associações de suas obras, com as analisadas por esta pesquisa. Como resultado, os parâmetros foram elencados e separados por categorias, demonstrando, assim, através de redesenho e fotografias, a presença de características modernas nos projetos elaborados pela arquiteta Josete Claudino, na Cidade de Cajazeiras, Paraíba.

Palavras chave: Arquitetura moderna. Modernismo. Cajazeiras. Josete Claudino.

ABSTRACT: The present work traces a profile to be used as a repertoire to search for the approximation between the works of the architect Josete Claudino and the modernist tendencies divulged by the main architects of this movement. With no intention of neglecting the history of modern architecture, but attentive to the main point of this research that are the characteristics of the modernist movement in Brazil, with a focus on the northeast region, a structure was built that departs from the points created by Le Corbusier for an ideal modern architecture. Following a logical connection between international modernism, reaching Cajazeiras, which is the place where the study object is located, which was used for analysis, with a subsequent need for a narrative that contextualized since the arrival of this architectural school in the country, with Gregory Warchavchik, going through São Paulo and Rio de Janeiro schools, entering the construction of Brasilia only to maintain the chronological order. The fact that really was present at the closing of this sequence was the arrival of the architect Acácio Gil Borsoi to Recife, and then to Paraíba. Due to the temporal and spatial proximity, Gil Borsoi was determined as a reference for the associations of his works with those analyzed by this research. As a result, the parameters were listed and separated by categories, thus demonstrating, through redesign and photographs, the presence of modern features in the projects elaborated by the architect Josete Claudino, in the City of Cajazeiras, Paraíba.

Keywords: Modern architecture. Modernism. Cajazeiras. Josete Claudino. 


\section{INTRODUÇÃO}

Na década de 1980, a produção arquitetônica no Brasil começa, de uma forma geral, a se diferenciar das décadas anteriores, onde o modernismo ainda era predominantemente o estilo mais utilizado pelos arquitetos nacionais. A expressão que a história classifica como pós-modernismo ainda necessita de um aprofundamento literal para que possa estar consolidada. As edificações produzidas nesse período podem ser comparadas com a produção europeia das décadas que a antecederam, e o desgaste ocorrido nas cidades pelas construções dos edifícios modernos começa a ser questionado pelos teóricos e pela sociedade em geral.

A partir de 1970, a produção artística já começava a demonstrar indiferença ao movimento modernista, e alguns artistas já consideravam o pensamento moderno como ultrapassado ou sem mais contribuições a serem acrescidas, além do que já retratavam a história. Arquitetonicamente, começou a existir uma ruptura com os princípios impostos pelo modernismo na sua origem, inclusive Costa (2012) atenta para o fato de que algumas correntes acabaram por dar início a um movimento voltado a adaptações inspiradas no estilo neoclássico, sempre com o intuito de se distanciar dos padrões modernos.

O termo "moderno" já havia sido utilizado por diversas culturas em épocas diferentes para registrar aquilo que era novo. Entretanto, para Bastos e Zein (2010), após 1940, a arquitetura moderna conseguiu efetivamente se concretizar, estando, até então, restrita a ocorrências excepcionais e isoladas. Isso ocorreu porque, no período entre guerras (1920-1939) os governos Fascistas que dominavam o mundo investiam muito mais em armas e na indústria bélica do que na construção civil. Os autores ainda afirmam que, após a destruição de várias cidades europeias, e frente à necessidade urgente da reconstrução das mesmas, fez com que a arquitetura moderna se tornasse viral definindo os modelos e características não apenas na Europa, mas a nível mundial. 
O objetivo principal desse trabalho é encontrar as características modernas nas edificações de autoria da arquiteta Josete Claudino na cidade de Cajazeiras. Ao concluir essa análise, pode-se elencar, em segundo plano, de que forma essas obras modificaram o cenário urbano da cidade, não apenas no setor residencial, mas também urbanisticamente falando, visto que a arquiteta fora a primeira mulher a assumir a SEPLAN (Secretaria municipal de Planejamento), e estando à frente deste cargo, reformou praças e requalificou espaços urbanos que se mantêm até os dias atuais com as mesmas formas criadas por ela.

Poucos registros existem sobre a autoria dos projetos arquitetônicos na cidade de Cajazeiras nas décadas anteriores a 1980, o que foi possível apenas com a chegada da arquiteta Josete Claudino à cidade. Com a sua ação à frente da SEPLAN, passou a atuar como incentivadora e fomentadora do registro de projetos arquitetônicos neste órgão municipal para a construção de edificações residenciais, comerciais e de serviço.

Sabido que, durante o recorte temporal escolhido, ainda não havia softwares para desenho arquitetônico, e com isso, muitos projetos acabaram se perdendo com o tempo, através de recursos como fotografia, entrevista com a arquiteta e com os proprietários das edificações analisadas e levantamento in loco do estado atual, foram confeccionados desenhos $2 \mathrm{~d}$ e maquete eletrônica $3 \mathrm{~d}$ das edificações como forma de tornar melhor ilustrado esse trabalho e proporcionar ao leitor um melhor entendimento sobre o estudo.

\section{METODOLOGIA}

O presente trabalho trata-se de uma pesquisa básica pura, descritiva, que se destina à coleta de informações através do contexto e referencial teórico, para a geração de um repertório que irá servir como base da análise sobre as obras da arquiteta Josete Claudino na busca por características modernistas.

Quanto ao seu procedimento, deve ser considerada bibliográfica, uma vez que serviram de consulta e citações livros e artigos já publicados. Por fim, também é 
uma obra documental, visto que permitiu ser feito o contraste entre as teorias apontadas na referência com a realidade através de documentos e fotografias.

A pesquisa tem o intuito não apenas de abordar uma realidade, elencando e analisando as edificações elaboradas pela arquiteta Josete Claudino, mas também de fazer uma interpretação para obter a compreensão do aparecimento de características da arquitetura moderna em sua obra.

A contribuição da arquiteta para essa pesquisa dá-se no entendimento de algumas nuances que dizem respeito à concepção da sua obra, tais como: escolha de materiais, estudos climáticos e, também, a perspectiva dos seus clientes sobre essas inovações na época em que os projetos foram concebidos.

A pesquisa se passa na cidade de Cajazeiras, localizada no alto sertão paraibano, no período compreendido entre agosto de 2018 e maio de 2019.

A pesquisa delimitou as entrevistas de acordo com a necessidade de coleta de dados importantes e relevantes para a construção da mesma. A preocupação com a ampliação dos sujetos de pesquisa deu-se pelo fato de haver mais informações para serem coletadas, analisadas e interpretadas. Dessa forma, tratando-se de um recorte temporal de apenas duas décadas, acabaria tornando-se repetitivo e cansativo o processo de inclusão dessas informações nesse trabalho. Dessa forma, foram incluídos somente aqueles que de fato poderiam trazer enriquecimento concreto para essa pesquisa.

A análise documental, ou análise de projetos neste caso específico, foi realizada através de desenhos técnicos em 2D, estruturados com o uso da ferramente auto cad, elaborados a partir de levantamentos locais ou do redesenho de plantas existentes. Essa etapa também contou com utilização de Overlay disponibilizado pelo município dos locais onde estão inseridas as edificações analisadas por esta pesquisa.

Para que fosse realizado o redesenho das edificações analisadas, a coleta de dados das mesmas foi organizada em uma tabela que forneceu dados importantes sobre a situação atual do imóvel. Havendo discrepância entre o estado atual do imóvel e o projeto original houve, então, a necessidade de duas plantas: um croqui da situação atual e a planta do desenho original da arquiteta. 
Contudo, para a análise das características arquitetônicas das edificações, utilizando a mesma corrente de pensamento de Melo (2013), observou-se a necessidade da elaboração de diretrizes para extração, de forma analítica, dessas características das edificações.

No que se refere à escolha dos procedimentos para análise de dados, levando-se em conta que existem inúmeros processos que levam a descodificação dos mesmos, Chizzotti (2006) afirma que, de fato, não existe uma técnica mais ou mesmo eficiente que a outra, mas, sim, a que melhor vai se adaptar a cada caso.

\section{RESULTADOS E DISCUSSÃO}

Maria Josete Claudino Martins Gomes nasceu em Cajazeiras, Paraíba, em 30 de dezembro do ano de 1958. Formou-se em Arquitetura e Urbanismo na Universidade Federal da Paraíba em 15 de setembro de 1981, vindo em 1984 para a cidade de Cajazeiras, onde atuou profissionalmente até o final da década de 1990.

Reconhecida por ser uma mulher culta e educada, Josete elenca como sendo seus principais referenciais na arquitetura, a arquiteta Lina Bo Bardi, Paulo Mendes Rocha e Acácio Gil Borsoi. Sendo Borsoi o perfil utilizado como parâmetro de análise comparativa dessa pesquisa, por possuir em sua obra particularidades que se assemelham às das obras relacionadas pela autora como objeto de estudo. Josete é pós-graduada em Projetos Luminotécnicos pela Universidade Castelo Branco, Rio de Janeiro.

Sua primeira obra como arquiteta na cidade de Cajazeiras foi a residência da família Figueired, situada na Avenida Padre Rolim. O impacto dessa edificação na paisagem urbana da cidade foi imediato, visto que a mesma estava implantada vizinho a biblioteca Pública Municipal, de frente a Praça da prefeitura e na mesma Avenida da Igreja Catedral Nossa Senhora da Piedade.

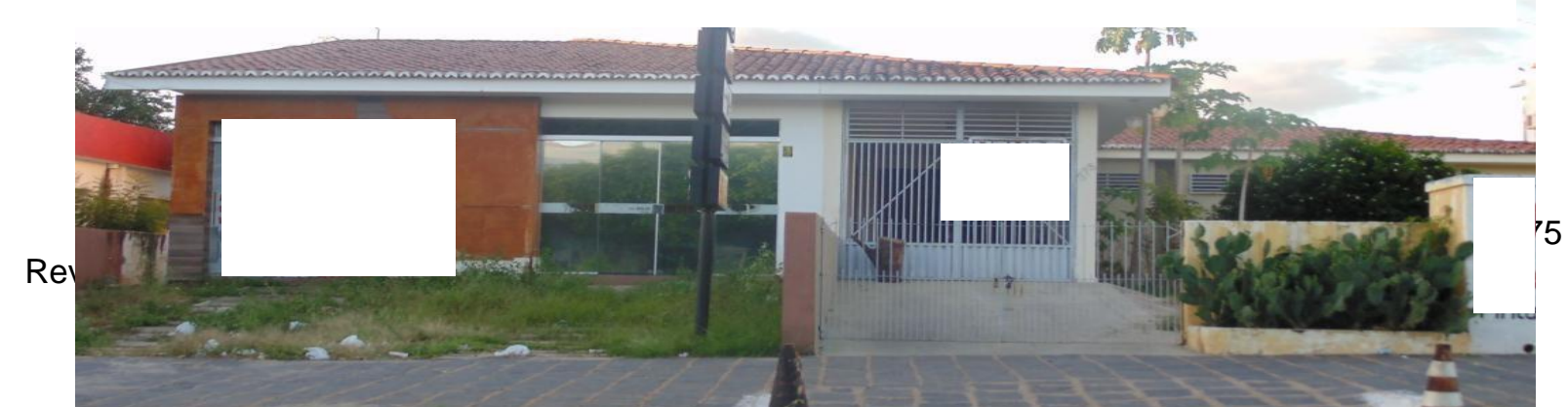


Figura 1 - Primeiro projeto de Josete em Cajazeiras, foto tirada em 04/2019. Fonte: acervo pessoal da autora.

Como é possível acessar através da figura 1, a edificação encontra-se com muitas avarias causadas pelo tempo e pelas intervenções em sua fachada original. Contudo, ainda é possível notar alguns elementos, tais como a implantação da casa no terreno em formato de $L$, criando um pátio na sua fachada sudeste, as venezianas nas esquadrias, o jardim com vegetação nativa e, principalmente, o telhado aparente com telha cerâmica, que diferenciava a edificação das existentes na avenida, como pode ser observado nas imagens a seguir:

Figura 2 - Casa da Arquiteta. 1990.

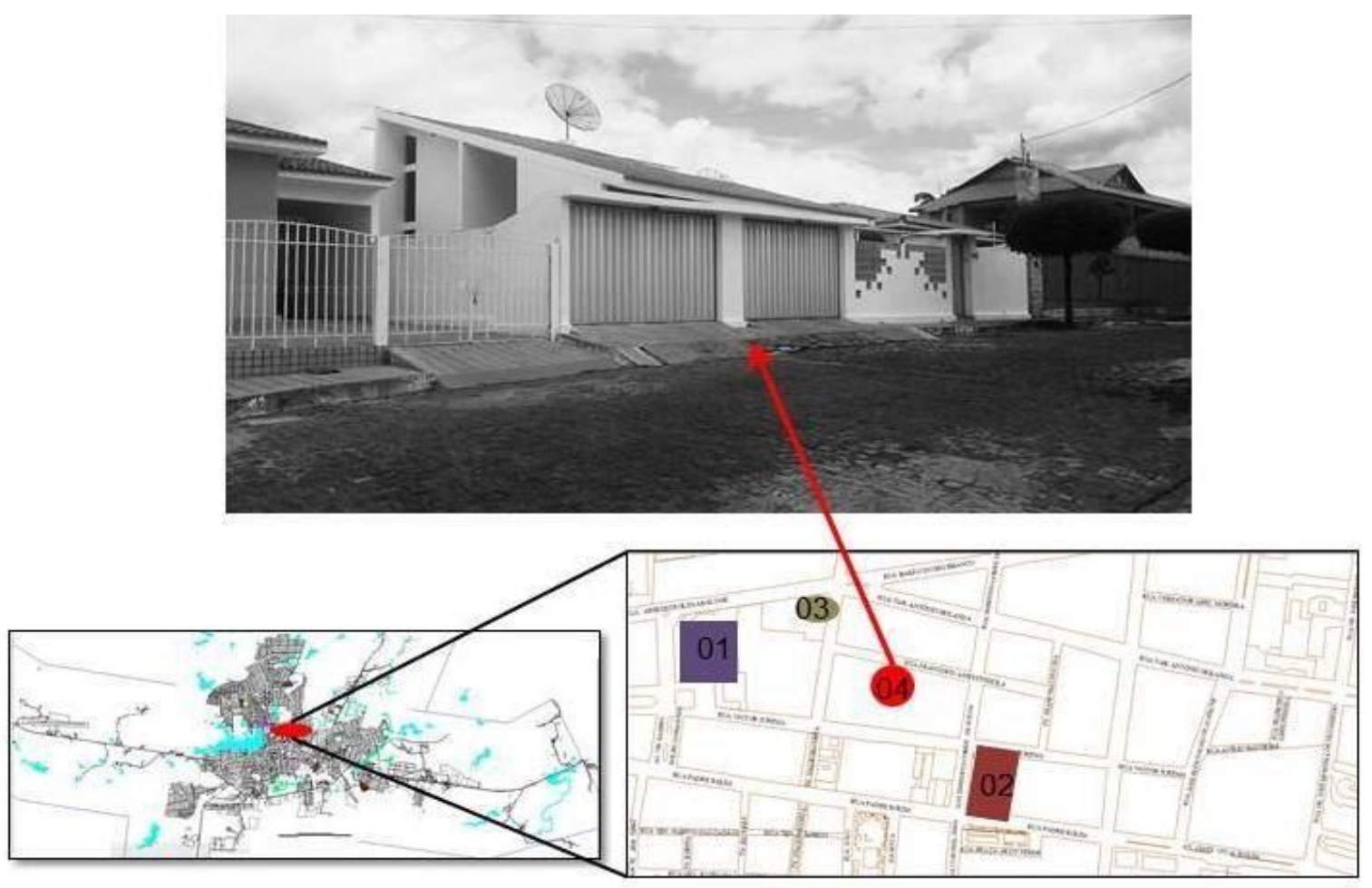


F.P.M. relembra em sua entrevista de como a arquiteta Josete Claudino tornou-se popular em um breve espaço de tempo: "Josete era uma mulher muito inteligente e educada, bastou seus primeiros projetos aparecerem para a mesma se tornar famosa em toda a cidade, todos ouviam falar sobre a arquiteta que fazia casas bem arejadas e quem não precisava acender a luz durante o dia". Foram exatamente essas características que tornaram Josete popular na cidade, as pessoas não queriam apenas uma casa bonita, elas esperavam morar em uma residência com ambientes confortáveis, porém, sem supérfluos, desejavam essas esquadrias tão faladas que "não precisavam ser abertas para ventilar" em suas moradias.

Nesse contexto, as duas edificações escolhidas para serem analisadas, a casa da Tamareira e a Casa Varanda demonstram a clara preocupação da arquiteta Josete Claudino em proporcionar conforto aos usuários das mesmas, desde os materiais e revestimentos até as soluções arquitetônicas aplicadas.

No jardim Adalgisa, está localizada a primeira edificação escolhida para ser analisada por este trabalho, a casa da Tamareira de 1990 (Figura 3).

Figura 3 - Casa da Tamareira. 1990.

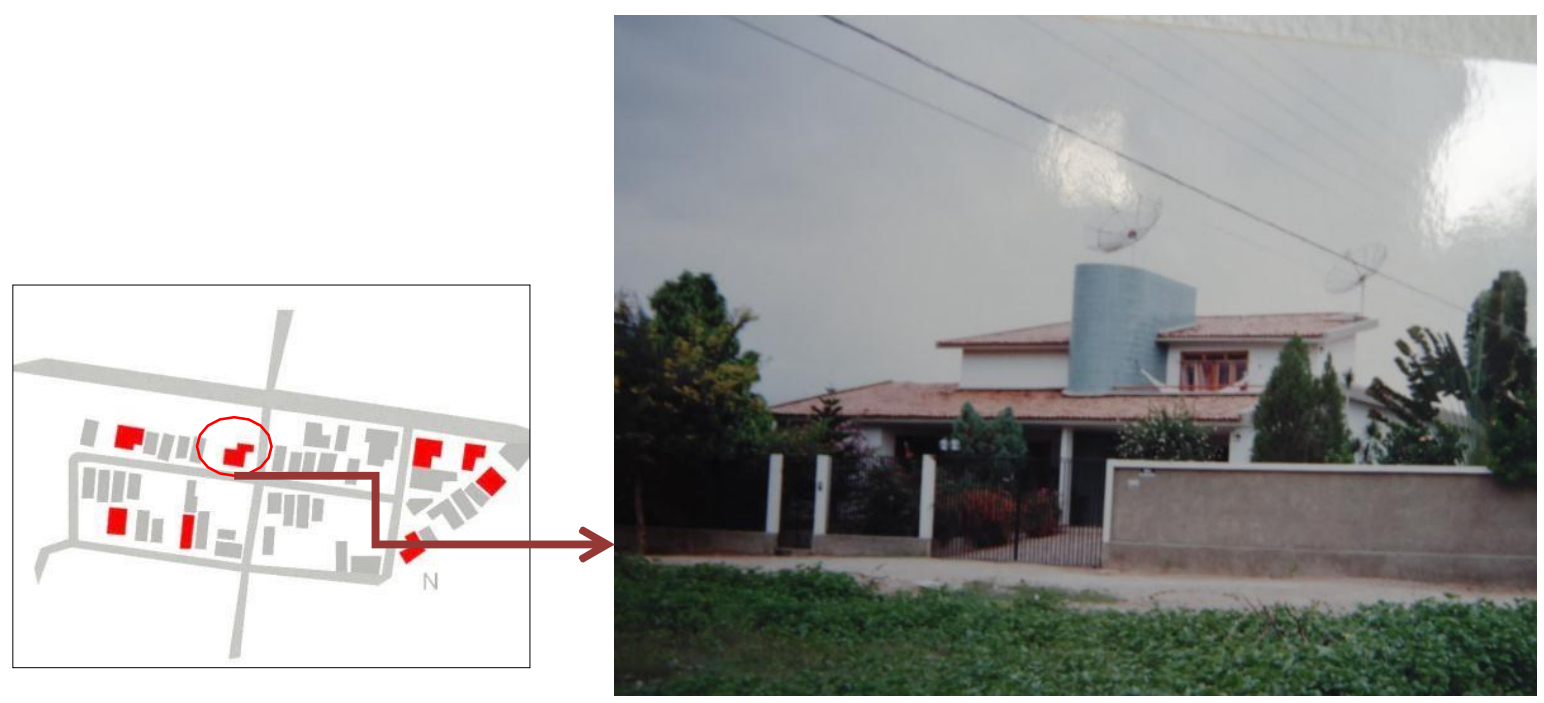

Fonte: a autora 2019. Fotografia cedida pela família. 
A "Casa da Tamareira" recebeu este nome devido uma Tâmara trazida de Israel pelo seu proprietário, que se sobressai no jardim dessa edificação, e pode ser vista mesmo por quem passa a duas quadras dali.

O centro de Cajazeiras possui um belo conjunto arquitetônico datado das décadas de 1930 até meados de 1960. Foi durante esse período que a cidade "tomou forma" e ganhou a constituição urbana que conhecemos atualmente.

A segunda edificação escolhida pela autora dessa pesquisa está localizada no centro de Cajazeiras. Essa obra é uma das mais bem conservadas da arquiteta nos dias atuais, sendo que até as arandelas originais compradas por Josete Claudino ainda servem de ornamento nos ambientes da casa. Intitulada de "Casa Varanda", a mesma foi construída em um terreno em declive acentuado, o que, na época da construção, causou muito espanto às pessoas que passavam, por ventura, naquele logradouro. Todos questionavam como seria possível construir uma casa com "um buraco" no centro do terreno. A solução encontrada pela arquiteta foi uma casa feita em três planos interligados por circulação vertical (escada). O nome "Casa da varanda" é em referência a sua varanda com floreira, que se tornou posteriormente uma das características da Arquiteta Josete Claudino.

Figura 4 - Casa Varanda.

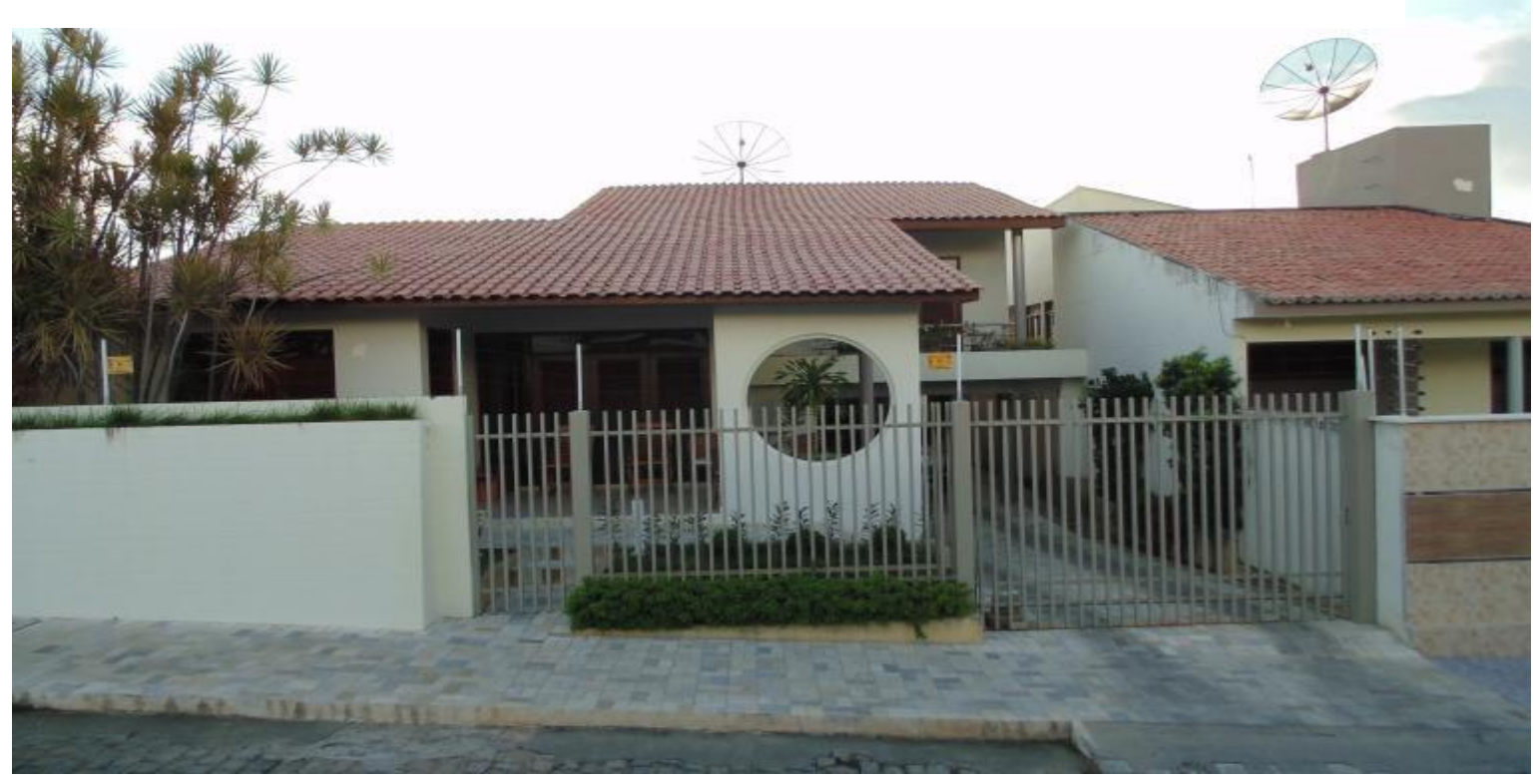


Foto: arquivo da autora, 2019.

Não há um registro exato de quantas obras a arquiteta realizou entre projetos de construção, reformas e ambientações na cidade de cajazeiras entre as décadas de 1980 e1990. Porém, através da narrativa apresentada até esse capítulo, já foi possível perceber que realmente o trabalho da arquiteta foi bem aceito e bastante propagado neste local. Porém, a arquiteta não trabalhou somente com obras residenciais; ela também foi responsável pela reforma da Praça Dom José da Mata (Praça da prefeitura), pela Praça Cardeal Arco verde (Praça da Catedral), pela praça do trabalhador na rua Dr. Coelho e pelo projeto do centro administrativo enquanto desenvolveu o papel de secretária de Planejamento do Município.

- A Casa da Tamareira.

Tabela 01 - Levantamento de imóvel existente.

\begin{tabular}{|c|c|}
\hline CASA 01 & CASA DA TAMAREIRA \\
\hline LOCALIZAÇÃO & $\begin{array}{l}\text { RUA JOSE LIBERATO DE ABREU/ LOTEAMENTO } \\
\text { JARDIM ADALGISA, } \\
\text { CAJAZEIRAS-PB. }\end{array}$ \\
\hline ANO DO PROJETO & 1990 \\
\hline JUSTIFICATIVA & $\begin{array}{l}\text { A PLASTICA, A VOLUMETRIA, E AS SOLUÇÕES DE } \\
\text { ACONFORTO }\end{array}$ \\
\hline ESCOLHA & $\begin{array}{l}\text { TÉRMICO DA EDIFICAÇÃO. BEM COMO A MEMÓRIA } \\
\text { AFETIVA DA AUTORA SOBRE A MESMA. }\end{array}$ \\
\hline $\begin{array}{l}\text { ÁREA DO TERRENO } \\
\text { ÁREA CONSTRUIDA }\end{array}$ & $\begin{array}{l}750 \mathrm{~m}^{2} \\
280 \mathrm{~m}^{2}\end{array}$ \\
\hline $\begin{array}{l}\text { ALTERAÇÕES NO } \\
\text { PROJETO ORGINAL }\end{array}$ & $\begin{array}{l}\text { APENAS REPAROS PARA CONSERVAÇÃO } \\
\text { EDIFICAÇÃO. }\end{array}$ \\
\hline
\end{tabular}

Figura 5 - Plantas casa da TamareiraFonte: redesenho da autora. 2019.

Pavimento superior

Ri

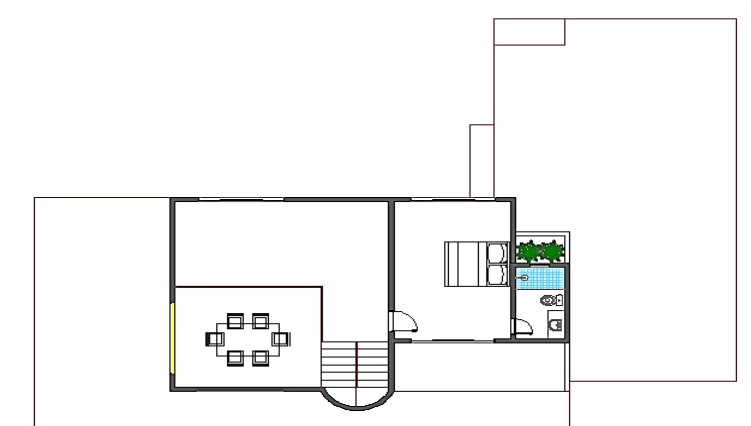

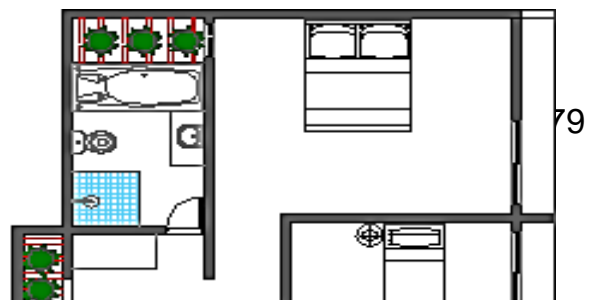


O primeiro parâmetro a ser analisado é a adequação ao clima local. Sobre este aspecto, Naslavsky (2004) discorreu acerca do uso de esquadrias com venezianas em madeiras e bandeirolas, sendo possível observar na figura 8 o aparecimento desses elementos tanto nas portas quanto nas janelas da edificação.

Figura 6 - Modelo das portas e janelas, Casa da Tamareira, 2019
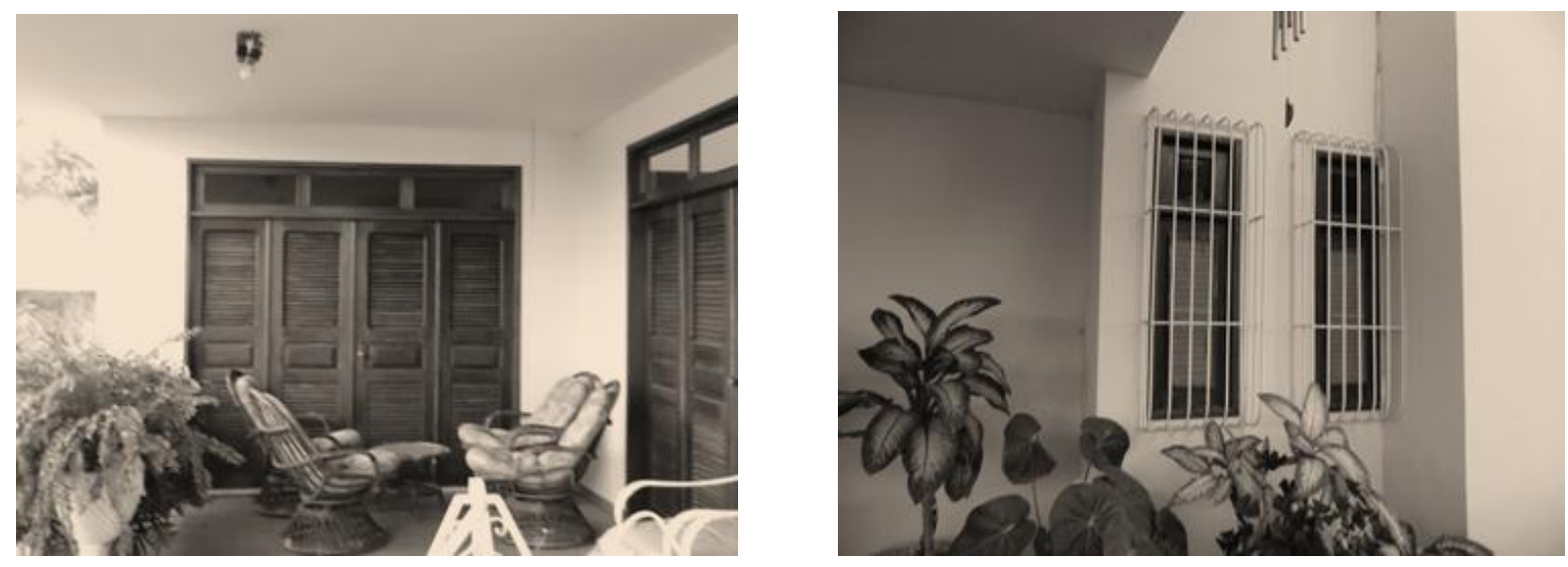

Fonte: acervo pessoal da autora. 
Casa das Tamareiras. Josete Claudino. Casa Otacílio Campos. Acácio Gil Borsoi.
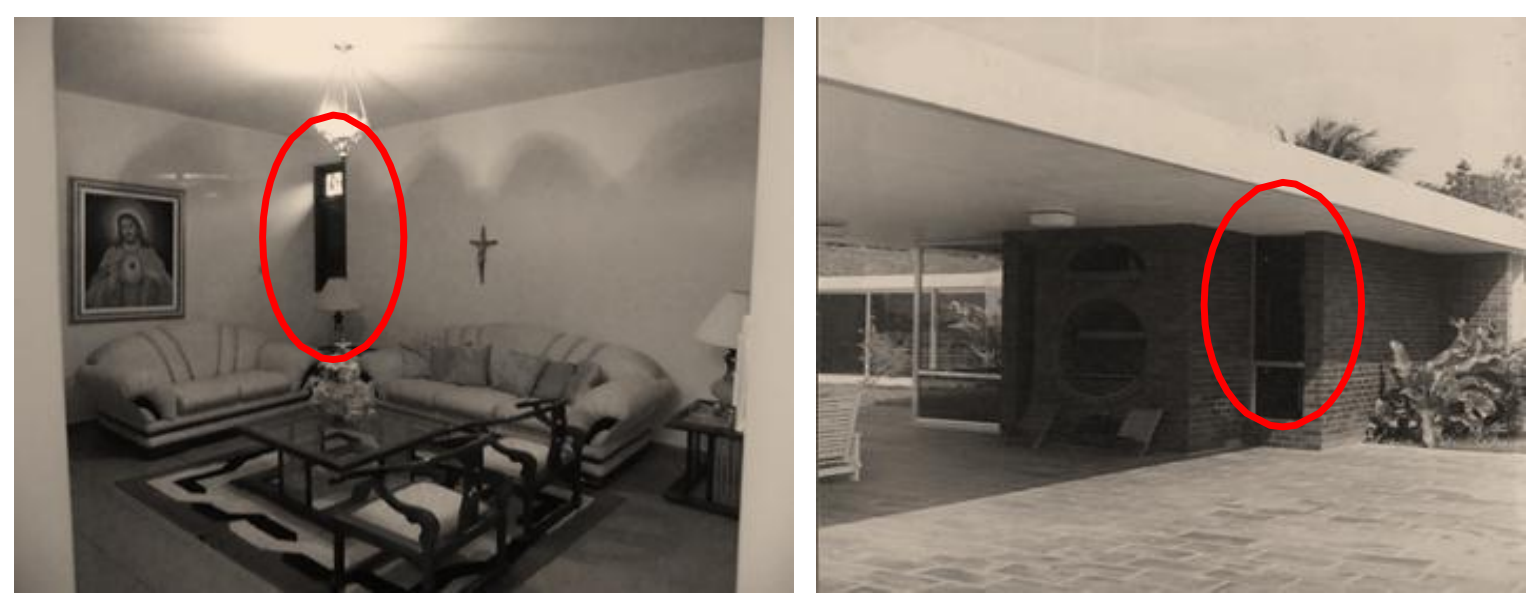

Foto: acervo da autora. 2019.

Fonte: Melo, 2013.

Outro elemento que pode ser destacado e associado com a criação de Borsoi são as esquadrias denominadas de "Seteiras" (janelas de 0,60 cm de largura e peitoril baixo).

$O$ belo e abundante jardim da edificação e as pedras utilizadas nos pergolados são elementos que fazem o contraste entre o natural com o industrial, desenhado pelo artista cajazeirense Nonato Saraiva, exclusivamente para esta edificação.

Neste contexto, é possível verificar a existência dessas características na casa da Tamareira, uma vez que a mesma possui sua planta com um fluxograma bem dividido entre área social, setor íntimo e de serviços. Separados verticalmente pela caixa da escada que quebra um pouco a horizontalidade da edificação. A planta em L, outra característica marcante da arquiteta, faz com que a edificação ganhe naturalmente um pátio que, nesta edificação. funciona como pomar.

Os acessos à edificação são dois: um para veículos e o outro para pessoas. A diferença entre níveis da rua para a edificação é de $0,60 \mathrm{~cm}$. No acesso de veículos, uma rampa ajuda a vencer esse aclive; já no de pedestres, o acesso dá-se por batentes. 
A diferença entre níveis dá-se apenas pelo fato de o terreno estar localizado em área plana, desta forma, além da manutenção de uma grande porção permeável no terreno, toda parte que não é edificada, essa diferença de pisos auxilia para evitar que águas pluviais revertam para o interior da edificação em caso de chuva torrencial.

Os materiais utilizados nos pergolados são: blocos de concreto, e pedras naturais (Ardósia) trazidas da cidade do Junco do Seridó que fica situada na Serra de Santa Luzia-PB, voltando, assim, ao contexto defendido por Naslavsky (2004) sobre o uso de materiais naturais associados ao industrializados.

Figura 7 - Pérgola que divide a sala de estar do hall dos quartos. Em destaque a pedra utilizada no revestimento da parede.
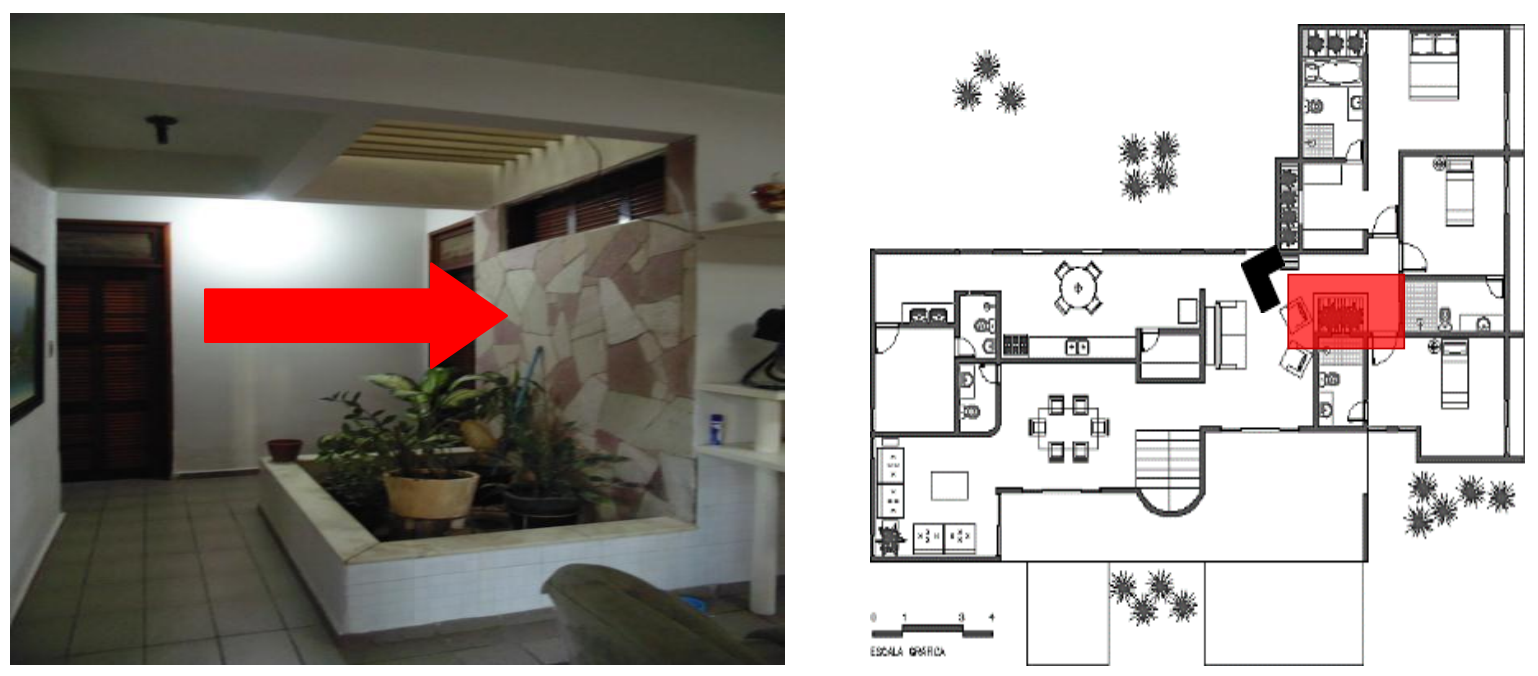
Fonte: foto da autora, 2019.

Outro ponto a ser identificado é a esquadria do banheiro de uma das suítes que não foi aberta para o exterior da edificação, mas, sim, para o pergolado.

As salas conectam-se gradativamente entre si e, através de grandes esquadrias, com o exterior da edificação. Ambas comunicam-se com o mezanino através de uma escada. O setor íntimo é resguardado por um hall que o separa do setor social, mantendo a privacidade destes ambientes. As suítes que compõem este setor, localizadas no leste da edificação, comunicam-se com os jardins do exterior através de grandes janelas com venezianas.

Um ponto em comum nas obras da arquiteta são os corrimões desenhados pela mesma, executados em madeira nobre.

A casa é toda pintada de branco, característica que permite um destaque às peças de madeira. O piso, ainda original, era da famosa marca "Santo Antônio", que, nas décadas de 80 e 90, predominavam nas escolhas dos arquitetos.

- $\quad$ Casa da Varanda

Tabela 02 - Levantamento de imóvel existente

CASA 01

CASA DA VARANDA

\begin{tabular}{|c|c|}
\hline \multirow{2}{*}{$\begin{array}{l}\text { LOCALIZAÇÃO } \\
\text { ANO DO PROJETO }\end{array}$} & $\begin{array}{l}\text { RUA FRANCISCO ASSIS DE SOUSA, CENTRO } \\
\text { CAJAZEIRAS-PB }\end{array}$ \\
\hline & $\begin{array}{l}1990 \\
A \quad \text { EDIFICAÇÃO S }\end{array}$ \\
\hline $\begin{array}{l}\text { JUSTIFICATIVA } \\
\text { ESCOLHA }\end{array}$ & $\begin{array}{l}\text { DA CONSERVAÇÃO TOTAL, AS SOLUÇÕES DO PARTID } \\
\text { PARA RESOLVER A DECLIVIDADE DO TERRENO FOI U } \\
\text { PONTO DETERMINANTE PARA } \\
\text { SUA ESCOLHA. }\end{array}$ \\
\hline $\begin{array}{l}\text { ÁREA DO TERREN } \\
\text { ÁREA CONSTRUID, }\end{array}$ & $\begin{array}{l}\text { O } 412 \mathrm{~m}^{2} \\
\text { A } 382 \mathrm{~m}^{2}\end{array}$ \\
\hline $\begin{array}{l}\text { ALTERAÇÕES } \\
\text { PROJETO ORGINAI }\end{array}$ & $\begin{array}{l}\text { NOAPENAS REPAROS } \\
\text { LL EDIFICAÇÃO. }\end{array}$ \\
\hline
\end{tabular}


Figura 8 - Plantas casa da varanda.

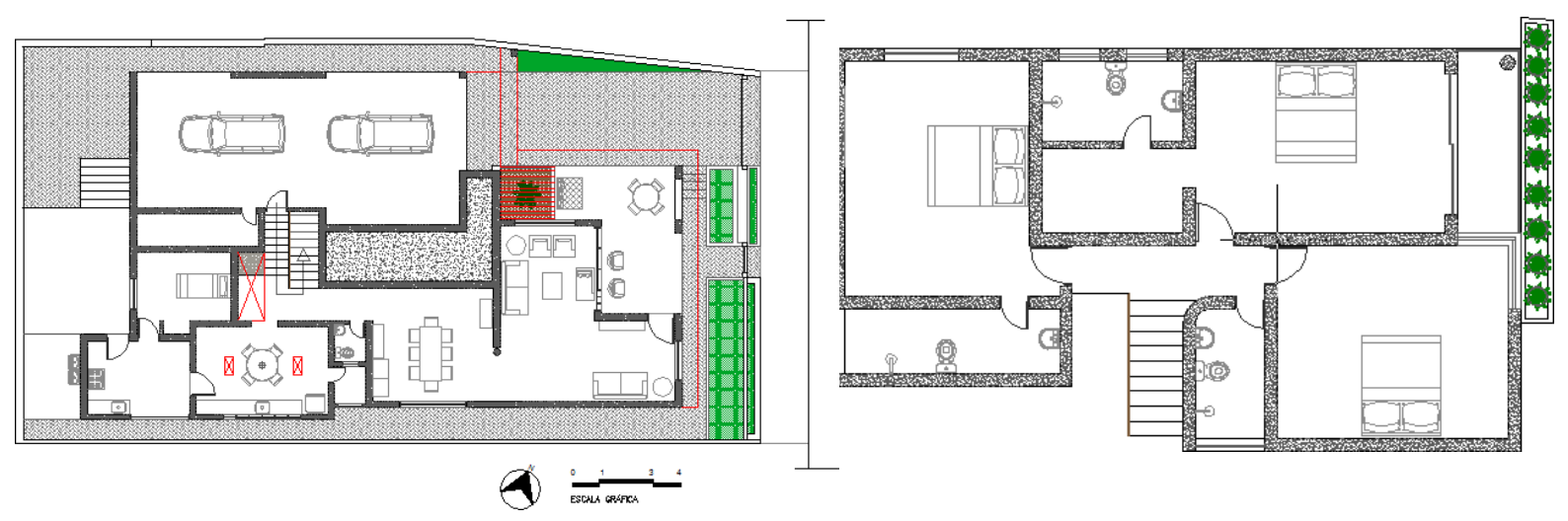

Fonte: Redesenho da autora. 2019. Feito após levantamento in loco.

Impossível passear pela Rua Francisco de Assis Sousa e não ter sua atenção roubada pela "Casa da Varanda". Situada em um terreno "difícil" e em declive lateral, o imóvel destaca-se pelo impacto causado no seu entorno.

Neste contexto, a análise da Casa da Varanda tem início com a sua implantação no terreno, e o estudo sobre seu impacto na vizinhança.

Figura 9 - fachada casa da varanda
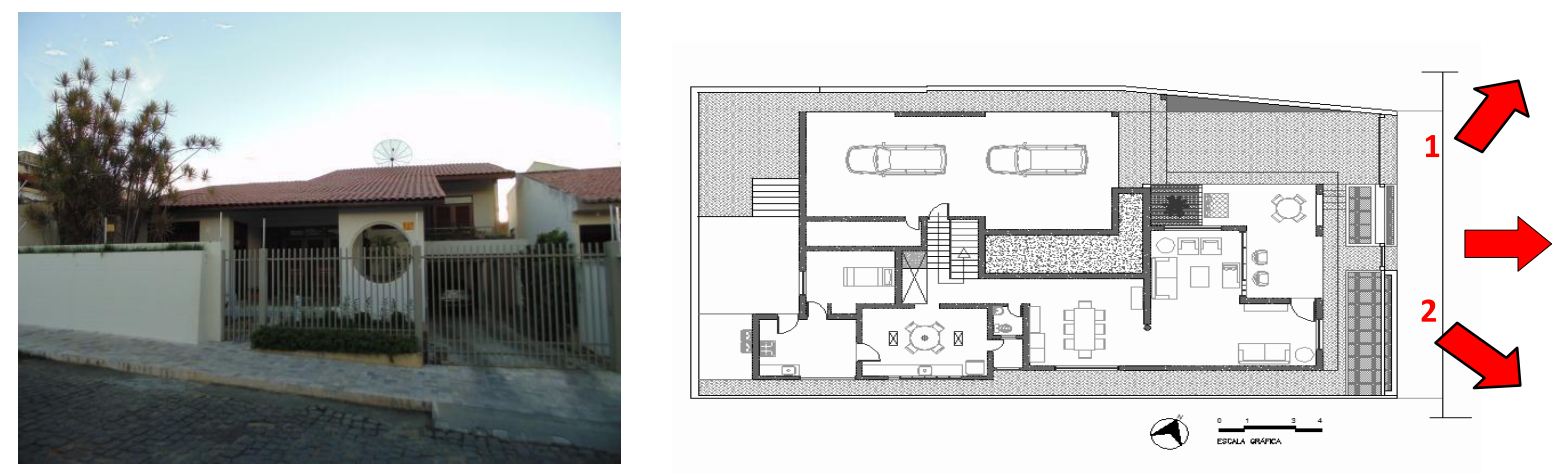

Fonte: acervo pessoal da autora, 2019.

As portas e janelas que são utilizadas na edificação, além de não permitirem o confinamento dos ambientes, mantendo sempre a ligação entre eles e o exterior da residência, ainda oferecem ventilação cruzada que, associadas ao uso dos zênites, promovem a renovação do ar dos ambientes, sem permitir que aconteça o 
efeito estufa nos mesmos. Esse é um dos fatores que mais assemelha a edificação com a arquitetura modernista brasileira: a adaptação ao meio.

A casa pode ser acessada basicamente por duas entradas frontais, uma para automóveis que acessa a garagem por meio de uma rampa, a outra para pedestres. Já dentro do lote, é possível acessar os ambientes da edificação por uma entrada principal que dá acesso às salas de estar e jantar. Quem chega à garagem acessa 0 interior por meio de uma escada, ou pela área de serviço (figura 10).

Figura 10 - Acessos.
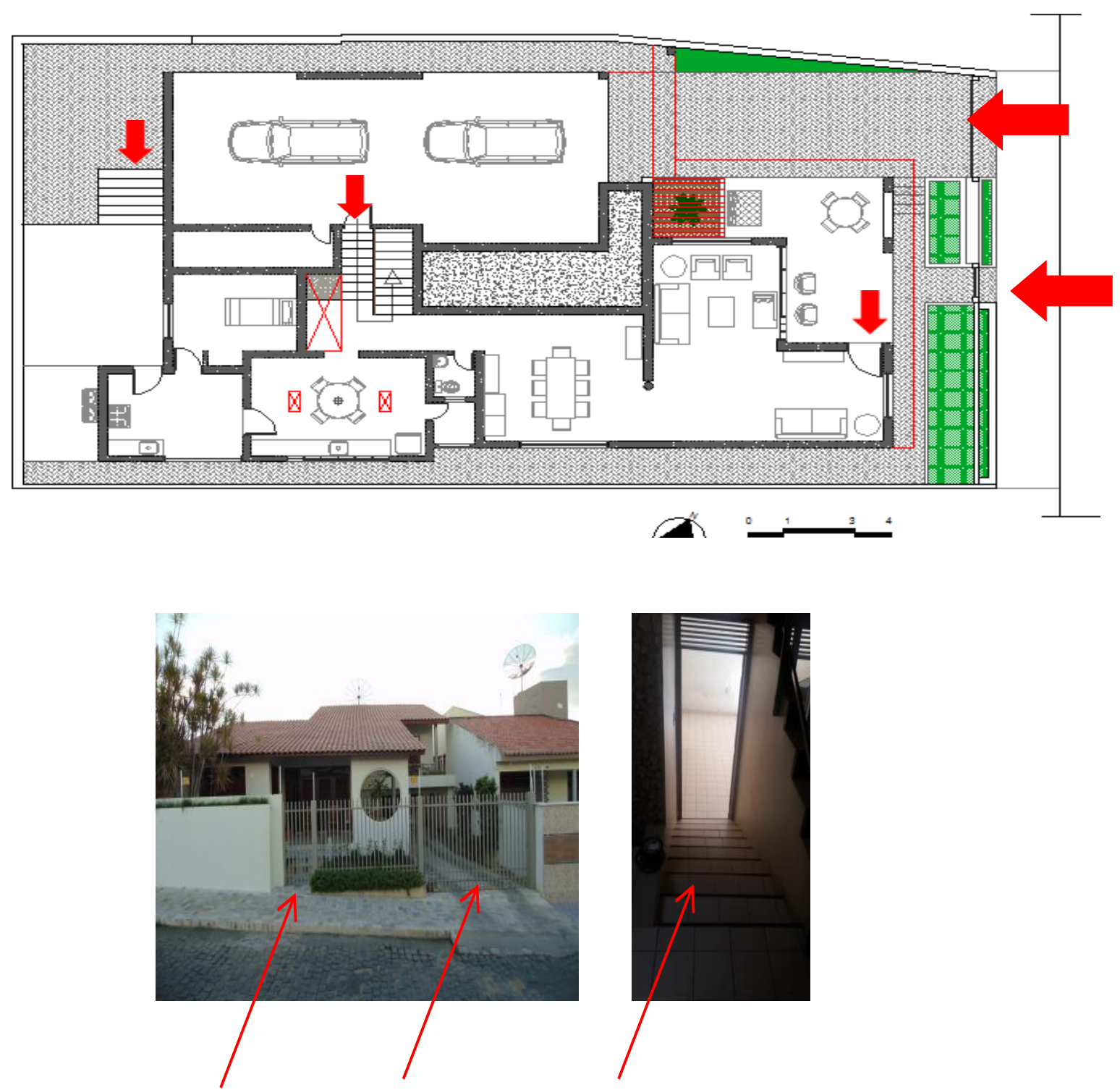

Acesso Social Acesso Veículos Escada de acesso na garagem. 
O terreno bastante acidentado da área onde a Casa da Varanda está localizada foi um grande desafio na concepção do seu projeto. No entanto, a arquiteta |Josete Claudino aproveitou dessa configuração para criar uma edificação completamente diferente das encontradas no local. A percepção da arquiteta em soltar a casa do piso, criando uma garagem sob pilotis, permite que o uso deste espaço que, porventura, viria a ser aterrado caso não houvesse esta solução, além de servir para abrigo dos automóveis, também é aproveitado em festas e confraternizações da família.

Novamente, teremos nesta edificação, tal qual a Casa da Tamareira já exposta por este trabalho, o uso de muitos elementos em madeira, aliados às pérgolas de concreto armado, que se complementam com pedras naturais.

A preocupação com a incidência de iluminação natural no hall de escadas levou a arquiteta a adotar o uso de um poço de luz no mesmo, onde, sendo coberto por uma claraboia, permite que o ambiente receba luz solar, ficando protegido de chuvas.

O piso interno da edificação (figura 11) é todo da cerâmica Santo Antônio, assim como os banheiros (piso e paredes), e os balcões de pias (banheiros e cozinha) são em granito.

Figura 11 - Revestimentos e bancadas.
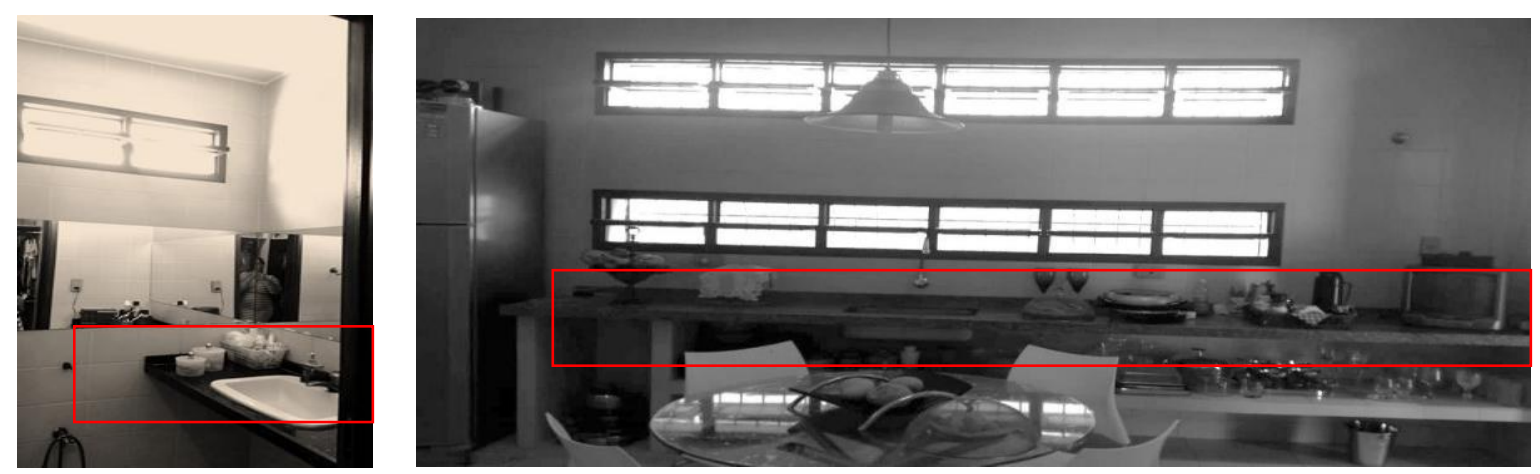

Fonte: arquivo pessoal da autora, 2019.

Como secretária de Planejamento do município de Cajazeiras, Josete atuou na sua competência em realizar seu sonho de ser Urbanista. Suas principais obras 
foram as reformas das praças Dom João da Mata, Cardeal Arco Verde e Praça do trabalhador.

Figura 12 - Primeira perspectiva, ainda em papel vegetal, da reforma da Praça Dom João da Mata.

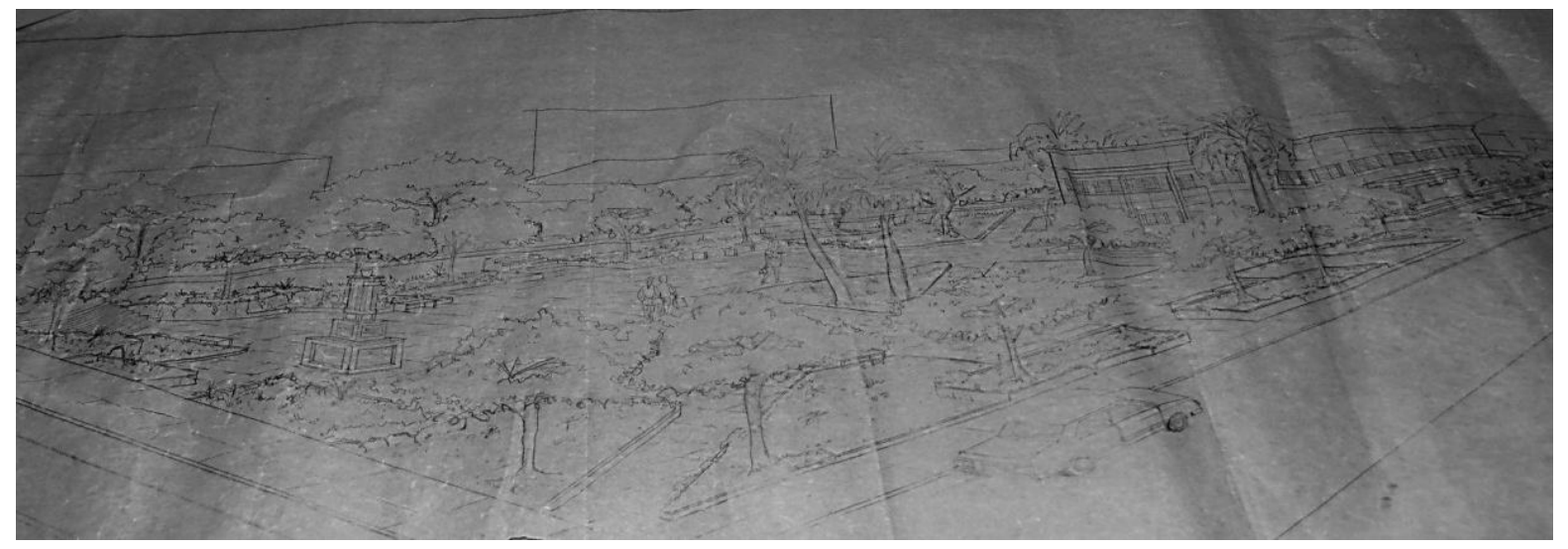

Fonte: foto da autora, extraída dos arquivos pessoais do desenhista da SEPLAN (Nonato Saraiva).

Após análise realizada em duas edificações projetadas por Josete Claudino, foi possível estabelecer quais os parâmetros utilizados pela arquiteta em seus projetos. As soluções arquitetônicas, quase sempre ligadas às características regionais, geográficas ou climáticas, foram significativas para a classificação do material analisado como moderno.

Na primeira edificação, a casa da Tamareira, o ponto alto é o conforto térmico da edificação, gerado pelo seu mezanino central, que serve como exaustor de calor. Não menos importante. foi relacionado também seu telhado cerâmico com inclinação de $25 \%$, que indica a adaptação do projeto ao meio onde está localizado, uma das características fortes do modernismo no Brasil. Levando para as análises comparativas com a obra de Gil Borsoi, algumas características ficaram bastante evidenciadas, por exemplo: a mistura de elementos naturais com industrializados, planta dividida por setores, planta como geradora natural de pátio, a horizontalidade quebrada por um eixo central.

Na segunda edificação analisada, a Casa da Varanda, além de se tratar de uma belíssima edificação, a mesma se projeta como grande potencial sustentável, 
no que diz respeito à economia energética gerada pelas soluções arquitetônicas adotadas na mesma, tais como: uso de zênite, pérgolas e janelas com venezianas.

\section{CONCLUSÃO}

Os resultados obtidos ao final foram satisfatórios, pois, apesar de serem concebidas em uma década distante do que a história classifica como o fim do movimento moderno, foram projetadas segundo os padrões da arquitetura moderna regionalista brasileira, amplamente difundida por Acácio Gil Borsoi, como pôde ser observado nos quadros que ilustraram esse capítulo de aplicação dos métodos para analises das obras.

Por fim, é possível concluir que a arquiteta Josete Claudino possui, em sua obra, características que the dão a possibilidade de ser classificada como uma arquiteta modernista. A mesma foi responsável por criar um modelo padrão de parâmetros a serem seguidos, posteriormente, para a concepção de casas eficientes no que se refere aos aspectos físicos e geográficos da cidade de Cajazeiras, Paraíba.

Como sugestão para trabalhos futuros, pode ser elencado o estudo mais aprofundado do modernismo na arquitetura da cidade de Cajazeiras, com as suas diferentes abordagens, desde as casas ecléticas dos anos 30 , passando pelo art décor dos anos 40, levantando melhor os dados das edificações dos anos 50 e 60. É importante destacar a preservação patrimonial da arquitetura moderna desta cidade, no entendimento de que a mesma ainda passa por um processo de crescimento, de forma que as futuras gerações possam entender melhor cada uma dessas etapas.

Como aprofundamento desta pesquisa, pode se destacar um estudo sobre as soluções Bioclimáticas presentes na obra de Josete Claudino, de modo que a mesma poderá servir para o embasamento inicial deste estudo. 


\section{REFERÊNCIAS BIBLIOGRÁFICAS}

ALVES, Z.M.M.B; SILVA, M.H.G.F.D. Análise qualitativa de dados de entrevista: uma proposta. Paidéia (Ribeirão Preto), Ribeirão Preto, n. 2, p. 61-69, Jul., 1992.

BASTOS, M.A.J.; ZEIN, R.V. Brasil: Arquiteturas Após 1950. São Paulo: Perspectiva, 2010.

BAUER, M.; GASKELL, G. (Eds.). Qualitative researching with text, image, and sound. London: Sage. 2008.

BENEVOLO, L. História da arquitetura moderna. 5. ed. São Paulo: Perspectiva, 1960.

BORSOI, A.G. Arquitetura como manifesto. Recife: Gráfica Santa Marta, 2006.

CHIZZOTTI, A. Pesquisa em ciências humanas e sociais. 8. ed. São Paulo: Cortez, 2006.

COSTA, A.A. As Cajazeiras que eu vi e onde vivi. João Pessoa: Gráfica Progresso, 1986.

COSTA, C. 0 pós-moderno na arquitetura nordestina. 2012. Dissertação (Mestrado) - Curso de Arquitetura e Urbanismo. Natal: Universidade Federal do Rio Grande do Norte, 2012.

COSTA, L. Documentação necessária. In: Cardoso et al. Arquitetura Civil II. São Paulo: USP, 1975. p.89-99.

COSTA, L. 1995. Lucio Costa: Registro de Uma Vivência. 2. ed. São Paulo: Empresa das Artes, 1995.

COSTA, R.X. Casas modernas na orla marítima de João Pessoa- 1960 a 1974. Dissertação (Mestrado em Arquitetura e Urbanismo) - Universidade Federal do Rio Grande do Norte. Natal, 2011.

FERNANDES, M. E. (1991). Memória Camponesa. In: REUNIÃO ANUAL DE PSICOLOGIA, 21. 1991, Ribeirão Preto. Anais... Ribeirão Preto, 1991.

FRAMPTON, K. História Da Arquitetura Moderna. São Paulo: Martins Fontes, 2003.

FLICK, U. Uma introdução à pesquisa qualitativa. Porto Alegre: Artmed, 2004.

GIL. A. C. Métodos e técnicas de pesquisa social. 6. ed. São Paulo: Atlas, 2010.

INFORZATO, R.R. Villa Savoye: Um passeio arquitetural a $30 \mathrm{~km}$ de Paris. 2014. Disponível em: <http://diretodeparis.com/villa-savoye-um-passeio-arquitetural-a-30-km-de- paris/>. Acesso em: 10 out. 2018.

JOSÉ Tavares Correia de Lira. Ruptura e Construção: Gregori Warchavchik, 1917-1927. Novos estud. - CEBRAP. n. 78, p. 145-167, 2007.

LANDIM, P.C. Desenho de paisagem urbana: as cidades do interior paulista. 1. ed. São Paulo: Universidade Estadual de São Paulo, 2003. MACIEL, C.A. Villa Savoye: arquitetura e manifesto. $2002 . \quad$ Disponível em:
<http://www.vitruvius.com.br/revistas/read/arquitextos/02.024/785>. Acesso em: 10 out. 2018.

MARQUES, S. Casas e casos: sobre modos de morar no Nordeste do Brasil. 2015. Dissertação (Mestrado em Arquitetura e Urbanismo) - Universidade Federal do Rio Grande do

Revista Interdisciplinar em Saúde, Cajazeiras, 6 (3): 170-190, jul./set. 2019, ISSN: 2358-7490. 
Norte. Natal, 2015.

MELO, M.D.T. Acácio Gil Borsoi: arquitetura residencial paraibana. 2013. Dissertação (Mestrado em Arquitetura e Urbanismo) - Universidade Federal da Paraíba. João Pessoa, 2013.

MOREIRA, F.D. Arquitetura moderna no Norte e Nordeste do Brasil: universalidade e diversidade. Recife: FASA, 2007.

MOREIRA, R. Repensando a geografia. In: SANTOS, M. Novos rumos da geografia brasileira. São Paulo: Hucitec, 1988.

NASLAVSKY, G. Arquitetura Moderna em Pernambuco 1951-1972: as contribuições de Acácio Gil Borsoi e Delfim Fernandes Amorim. 2004. Tese (Doutorado em Arquitetura e Urbanismo) - Universidade de São Paulo. São Paulo, 2004.

LIMA, P.P.S. Estratégias Bioclimáticas Na Arquitetura Moderna De João Pessoa: Análise aplicada em três residências produzidas entre as décadas $1950-1980.2015$.

230 f. Dissertação (Mestrado em Arquitetura e Urbanismo) - Universidade Federal da Paraíba. João Pessoa, 2015.

SILVA FILHO, O.L. Na Cidade da Parahyba: o percurso e as tramas do moderno. 1999. Tese (Doutorado em História) - Universidade Federal de Pernambuco. Recife, 1999.

STAUBLI, W. Brasília. New York: Leonard Hill Books, 1966.

STRÖHER, R.A. A fachada frontal da Villa Stein: um exorcismo corbusiano. 2005. Disponível em: http://www.vitruvius.com.br/revistas/read/arquitextos/06.065/417>.

TEIXEIRA, E. B. A análise de dados na pesquisa científica: importância e desafios em estudos organizacionais. Desenvolvimento em Questão. v.1, n. 2, 2003. p. 177-201.

ZEIN, R.V.; BASTOS, M.A. Brasil: arquiteturas após 1950. São Paulo: Perspectiva, 2011. 